\title{
Mechanical Properties of Recycled Tire Wires and Glass Fibers Reinforced Concrete
}

\author{
Moti Muleta*, Tesfaye Alemu \\ Faculty of Architecture and Civil Engineering, Addis Ababa Science and Technology University, Addis Ababa, Ethiopia \\ Email address: \\ muletamoti@gmail.com(M. Muleta),Tes.alemu@gmail.com(T. Alemu) \\ ${ }^{*}$ Corresponding author
}

To cite this article:

Moti Muleta, Tesfaye Alemu. Mechanical Properties of Recycled Tire Wires and Glass Fibers Reinforced Concrete. International Journal of Engineering Management. Vol. 4, No. 1, 2020, pp. 1-10. doi: 10.11648/j.ijem.20200401.11

Received: November 6, 2019; Accepted: November 26, 2019; Published: April 14, 2020

\begin{abstract}
Concrete is a versatile construction material with various uses. It is has poor tensile strength and good compressive strength mechanical properties. In past, an effort has been made to improve concrete mechanical properties by mixing with various foreign materials such as synthetic and natural fibers, steel wires and plastics. However, there is research gap in literature to study comparative use of recycled and new materials for improving concrete mechanical properties. This research work experimentally investigates use of new glass fibers and recycled tire fibers in $0.5 \%, 1 \%$ and $1.5 \%$ in weight mixes with concrete to study concrete mechanical properties performance gains such as compressive, flexural and split tensile strength properties. Experimental results indicated as compared to control plain concrete specimen, use of recycled steel fiber and glass fibers in concrete mix increased flexural property of concrete by $19.64 \%$ and $24.56 \%$ whereas split tensile strength of concrete is enhanced by $8.15 \%$ and $12.02 \%$, respectively. Similarly, compressive strength of concrete is improved by $5.34 \%$ and $7.87 \%$ respectively. Also, optimum blend percentage of recycled tire fiber and glass fiber for enhanced performance gains in concrete mechanical properties is one percent. Finally, use of recycled steel fibers and glass fibers in concrete exhibited similar concrete mechanical property performance gains however, recycled steel fibers has $78 \%$ direct cost reduction as compared to glass fibers.
\end{abstract}

Keywords: Glass Fibers, Recycled Tire Fiber, Compressive Strength, Flexural Strength, Split Tensile Strength, Admixture

\section{Introduction}

\subsection{General}

Concrete is a common and most frequently used in construction industry and which is composite material made up of inert material of different size, which is bound together with hydraulic binding material. The strength of concrete is depending on the strength of aggregate paste bond. Concrete is a brittle material which has low tensile strength, in the past attempts have been made to improve this Weak properties by using conventional reinforcement. [1-2]

Brittle materials are a material type which does not have significant post-cracking ductility. To provide improved mechanical properties Fibrous composites have been and are being developed. When this brittle material loaded with tension initially deforms elastically and this repose followed by micro cracking, localized micro cracking and finally fractures. Application fibers into the concrete changes post elastic property in various ranges, depending on factors, types, modulus and aspect ratio of fiber, fiber matrix strength, fiber properties and strength, fiber bonding characteristics, fiber content and aggregate size effects. [3]

Fibers can upgrade the long term serviceability of the structural component. Serviceability of the structure is the ability to maintain its strength and interconnection to provide its function for designed life service. [3] Fiber reinforcing material which can prevent occurrence of large cracks and which has possessing certain Characteristic properties, steel fibers can be circular or flat by shape and fiber is often described by a convenient parameter called "aspect ratio". The aspect ratio of fibers is the ratio of its length to its diameter basically ranges from 30 to 150 . Most commonly commercial available and manufacture fibers are from steel, plastic glass, organic polymer, naturally occurring fibers and vegetable fibers [1-3]. 
Glass fiber is a recent introduction in making fiber concrete. It has very high Tensile strength vary from 1020 to $4080 \mathrm{~N} / \mathrm{mm}^{2}$. Furthermore they are quite economical and hence glass fibers are the most commonly used fibers for structural applications. The structure of the reinforcing glass fibers has required the development of special technologies to incorporate the fibers into the matrix and also Steel fiber is one of the most predominantly used fibers. Generally round fibers are used. The diameter of round steel fiber may vary from 0.25 to $0.75 \mathrm{~mm}$. The steel fibers are likely to get rusted and lose some of its strength but investigations have shown that the rusting of the fiber takes place only at the surface. [24]

\subsection{Statement of the Problem}

Concrete has good compressive strength but it has poor tensile strength. However, this poor tensile strength can be improved by use of fibers such as recycled tire wire and glass fibers in various proportion and length. This addition of fibers especially in this research recycled fibers also promotes green construction. This is a step forward in construction industry where use of great deal of virgin materials for concrete production is not uncommon.

This research work fills in perceived void in literature by experimentally investigating mechanical properties of dual recycled tire wire and glass fibers mixed structural concrete.

\subsection{General Objective}

Main objective of this research work is to investigates mechanical properties and establish performance gains of structural concrete modified with dual mix of recycled tire wire and glass fibers.

\subsection{Specific Objective}

1. To investigate the mechanical properties of concrete with recycled tire wire and glass fibers.

2. To determine optimum blend percent of recycled tire wire and glass fiber for maximum concrete performance gain.

3. To compare direct production cost of conventional concrete and recycled tire wire and glass fiber mixed concrete.

\subsection{Significance of the Study}

Construction industry is a booming sector here in Ethiopia and use of alternative materials as opposed to traditional construction materials is uncommon. So this research pushes a way forward for potential application of alternative materials in construction industry by studying mechanical properties of recycled tire fiber and Glass fibers modified concrete.

\subsection{Methodology}

To achieve the objectives outlined in this research work, the study was made in the following ways. The research specifically focuses on the mechanical properties of glass and recycled steel fiber reinforced concrete. The experimental study mainly start with characterization of concrete ingredients and all important tests were made for both fine and course aggregate in the production of concrete and all the required properties are in conformity with Ethiopian standard. After production of concrete and carrying out test on the fresh concrete the specimen for the testing of mechanical properties of hardened concrete were prepared by pouring concrete to adjusted different molds.

In each mix of concrete, Mixing was made keeping every condition the same except varying the glass and recycled steel fiber amount start from $0.5 \%, 1 \%$ and 1.5 . Final the mechanical properties including compressive strength, Flexural Tensile strength and split Tensile strength were conducted at the age of $7^{\text {th }}$ and $28^{\text {th }}$ days.

\section{Literature Review}

\subsection{Introduction}

Concrete is produced from a mixture of two components, Aggregate and cement paste and which has low tensile strength, low flexural strength and strain capacity at fracture. These mechanical behaviors of concrete problem are solved by adding reinforcing bars and also by restraining techniques. Reinforcing steel is continuous throughout the structure and fibers are discontinuous and are generally randomly distributed in a concrete. [4]

\subsection{Fibers}

Fiber is a material which has a length to diameter ratio ranges from 30 to 150 and they can be circular or flat in shapes. In plain concrete and material which has brittle properties shows micro cracks development even before loading, this happens particularly due to drying shrinkage or other causes of volume changes and also when loaded, the micro cracks propagates and open up, and owing to the effect of stress concentration, additional cracks happen in places of minor defects. $[6,7]$ The structural cracks proceed slowly by change of direction in bypassing the more resistant constituent in matrix; the development of such micro cracks is the main cause of inelastic deformation in concrete. It has been recognized that the addition of small, uniformly dispersed and closely spaced and dispersed fibers to ingredients of concrete would act as crack controller and would substantially improve its static and dynamic properties, this type of concrete is known as fiber reinforced concrete. Fiber reinforced concrete is a composite material consisting of cement, aggregates, water and discontinues discrete and uniformly dispersed fibers. Although every type of fiber has been tried out in cement and concrete, not all of them can be effectively and economically used, each type of fiber has its characteristic properties and limitations. Some of fiber that could be used are steel fiber, polypropylene fiber glass fiber, nylon and other Different types of fiber are stated and discussed below. [24] 


\subsubsection{Steel Fibers}

Steel fiber is a type of fiber and one of the most predominantly used fibers. In terms of shape round fibers are mostly used. The diameter of round steel fiber may vary from 0.25 to $0.75 \mathrm{~mm}$. The steel fibers are likely to get rusted and lose some of its strength but investigations have shown that the rusting of the fiber takes place only at the surface. Basically steel fibers improves the mechanical properties of concrete. It has be commonly used in various types of structures particularly for used overlays of roads, airfield pavement and bridge decks. [11, 24]

\subsubsection{Glass Fibers}

Glass fiber is new advancement in using as a fiber in the production of reinforced concrete. It has very high Tensile strength vary from 1020 to $4080 \mathrm{~N} / \mathrm{mm}^{2}$. Furthermore they are quite economical and hence glass fibers are the most commonly used fibers for structural applications. The structure of the reinforcing glass fibers has required the development of special technologies to incorporate the fibers into the matrix. A particular problem that also had to be dealt with was the low alkali resistivity of the glass fibers. To overcome this this problem special alkali resistant glass formulations (AR glass fibers) had to be used or alternatively E glass fiber was to modify the matrix in order to improve the resistance of the fibers either by lowering the alkalinity level by using silica fume additions, high alumina cement. Application of GFRC has been the manufactured of exterior building façade panels. This application makes up at least $80 \%$ percent of all GRFC architectural $[5,9]$ and structural components in the US. Another large application of GFRC is surface bonding, surface bonding is new building concept used extensively for small commercial buildings as well as for sealing walls and also been used in mining application. $[1,24]$

Types of glass fiber

A-glass fiber:

A glass fiber is one of the most commonly used glass fibers with a composition of soda lime glass with high alkali content which ranges between $10-15 \%$ and mostly recommended in areas which chemical attacks are available.

C-Glass fibers:

$\mathrm{C}$ class glass fibers is mostly used and recommended in water pipe and tank manufacturing and it shows a resistance to chemicals.

E-glass Fiber:

E-class glass fiber shows Lower alkali content $(<1 \%)$ and strong tensile, compressive strength and stiffness with good electrical properties and relatively low cost. E glass fibers have low impact resistance. The physical properties of EGlass fibers are listed below. [9, 17]

1. High strength and stiffness

2. low density

3. Non-flammable

4. Relatively has good chemical and heat resistance

5. Relatively insensitive to moisture

6. Able to maintain strength properties over wide range of condition

7. cheap cost

\subsection{Recycled Tire Fiber}

Waste tires have been a major international waste management problem, in Ethiopia according to Horizon Addis tire factory market demand prediction Ethiopia's annual tire demand is estimated around 1.1 million. And it is believed that an estimated 1.1 million tire is discarded ever 23 years.

Tire is a material that produced from different components which include rubber and steels. The material used in the production of tire includes rubber, synthetic rubber compound, steel, polymeric fiber, fabric,. The material and percentage used in tire are primarily a function of the vehicle and usage. [25]

\subsubsection{Recycle and Reprocess Waste Tire}

Tires can be shredded, granulated or crumbed so the shredded or crumbed rubber can be used in other application. The tire case is which makes difficult to separate the steel and textile reinforcement from the rubber. However the following discussed methods are used to reprocess waste tire. $[23,25]$

Pyrolysis process

The pyrolysis process is the commonly used method to recycle tire which minimizes atmospheric emissions. The process starts with heating and/or burning in an enclosed pyrolysis plant chamber, this process producing fuel oil, steel wire and carbon black. The fuel oil can be used for different purposes including energy source and also the steel wire can be used for different purposes. Steel fibers recycled by method of pyrolysis process. Recycled steel fiber; they are mostly containing black carbon on the surface. The tensile strength is not as much affected in the process. [23]

Crumbing

Crumbing is the process of reducing rubber compound to a fine granular form. crumbing has been made more difficult by the development of the modern steel braced tires, uses of rubber crumb includes landscaping mulch, underlay/carpet backing, wire and pipe insulation, adhesive and may more. [23]

\section{Cryogenic fragmentation}

Cryogenic fragmentation is one of the methods used to recycle waste tire and gives the output by separating components like rubber.

Gasification

Gasification is the process of converting a waste tire material into a gas which can be used as fuel. Gasification processes can be used on tire to produce clean gas for power generation and chemical manufacture. [23]

\subsubsection{Application of Recycled Steel}

Application waste tire for various purposes such as for land fill engineering, motorway embankment, crash barrier erosion control and artificial reefs. The reprocess and recycled of tires can be granulated, shredded and pyrolysis 
process and arranged for the intended use. However tire shredding and pyrolysis process are the most common methods in retrieving steel fibers from waste tire. The shredding process takes place in variable stages, with output of steel fibers, rubber pieces and granules are obtained.

Steel fibers recovers by method of pyrolysis are contain black carbon on the surface but which didn't change the mechanical properties and it takes to decrease in a range of 10-15 [23].

\subsection{Previous Works Related to Fiber Reinforced Concrete}

laboratory analysis of fiber application with three different level of volume the compression, splitting, three point load, bending and impact test was conducted and by replacing cement with silica fume in the reinforced self-compacting concrete with recycled steel fibers and studied the mechanical behavior and impact resistance and the combined effect of silica fume and impact resistance depending on the result a linear percentage of silica fume replacing, After analytical study empirical equation was developed by regression analysis and from the conducted result replacement of silica fume and recycled steel fibers reduce workability of concrete and the combined effect of them improve the impact resistance and mechanical properties of concrete. [14]

A study on glass fiber as an additive in concrete to increase concrete tensile strength in percent 0 to $1 \%$ has been studied for the effect on mechanical properties of concrete by carrying tensile, compressive and flexural strength tests and its observed that the addition of glass fiber with $0.1 \%$ shows better result in mechanical properties of concrete. [19]

Experimental Investigation on the properties of concrete beam which including the flexural and shear behavior by using a symmetrical two point concentrated static loading system and the result of using glass fiber as additive is highly effective in flexural and shear strength of beams. [18]

Experimental study on usage of class E-glass fiber in the concrete is investigated with percent of glass fiber $0.5,1$, $1.5 \%$ respectively and laboratory test was conducted on compressional, split tensile and flexural strength. The addition of glass fiber into the concrete is improves the compressive, tensile and flexural strength at 28 days and the addition with $1 \%$ glass fiber shows a better result. [21]

Experimental study is conducted on the strength and durability aspect study of glass fiber concrete with fly ash in percentage of $25 \%$ and woven glass fiber $0.1,0.2,0.3 \%$ respectively and the experimental study indicates that the addition of glass fiber with $0.2 \%$ gives higher strength than the other concrete mix. [22]

The experimental and numerical characterization of the bond behavior of (SFRT) steel fibers recovered from tire and try to figure out in the cementitous matrices. The output of an experimental investigation focused on the tensile response of the steel fibers and their bond with cementitious matrices are discussed and reported. Within a comparison between experimental and result and numerical prediction result of the pullout behavior of recycled steel fibers in a concrete is presented and satisfactory output was found between them. [15]

The numerical and experimental studies on the use of recycled fiber (RSFRC) in failing of elements in bending and shears, The conducted study using recycled steel fibers as a shear reinforcement in reinforced concrete beam. By conduction three point load laboratory test for bending test and modeling of RSFRC beams failing in shear. [17]

The use of steel fibers recovered from tire and granulated rubber in concrete improved in the fragile matrix mostly in terms of toughness and post cracking behavior and recycled steel can be used for structural and none structural application. [15]

The studies about the resistance of concrete containing polypropylene or steel fibers were studied and the laboratory analysis that uses both fibers increased the strength and fire resistance of concrete. [13]

The plastic shrinkage and permeability of polypropylene fiber reinforced concrete and test result the shrinkage behavior of concrete was change (improve) by using fibers, and also the authors also discussed that addition off polypropylene fiber increase the gas and water permeability coefficient. [12]

From the deep investigation of literature review it has been observed that there is a gap in detail study and investigation conducted on the comparison effect on mechanical properties between recycled fiber and industrially manufactured glass fibers. Investigation has been done by different percentage of both fibers with $\mathrm{C}-25$ conventional concrete.

\section{Material and Methodology}

\subsection{General}

To achieve the objectives outlined in this research work, the study was made in the following ways. This research specifically focuses on the mechanical behavior of glass fiber reinforced concrete and recycled steel fiber from waste tire concrete. The experimental study mainly start with characterization of concrete ingredients and all important tests were made for both fine and course aggregate in the production of concrete and all the required properties are in conformity with Ethiopian standard. After production of concrete and carrying out test on the fresh concrete the specimen for the testing of mechanical properties of hardened concrete were prepared by pouring concrete to adjusted different molds. In each mix of concrete, Mixing was made keeping every condition the same except varying the glass and recycled steel fiber amount start from $0.5 \%, 1 \%$ and 1.5 . Final the mechanical properties including compressive strength, Flexural Tensile strength and split Tensile strength were conducted at the age of $7^{\text {th }}$ and $28^{\text {th }}$ days.

\subsection{Experimental Program}

The main goal of the thesis is to prepare C-25 grade concrete made with recycled tire fiber and glass fiber to characterize its properties, in fresh and hardened state to 
determine the mechanical properties. A glass fiber and recycled tire wire fiber with length of $25 \mathrm{~mm}$ was used within a dual mix to produce a C-25 concrete grade. A concrete grade C-25 for normal strength was used with three different volume of recycled tire wire and glass fiber of $0.5,1,1.5$ percent, including control mix for each mix design.

The mechanical properties for the control mix and performance gain for the recycled tire fiber and glass fibers with the stated varying percentage was tested. The test obtained in the fresh state of concrete including slump test and compressive, split tensile, flexural strength at hardened state.

\subsection{Material}

\subsubsection{Cement}

In this research work, all the mixes were prepared using Dangote cement.

\subsubsection{Coarse Aggregate}

The course aggregate used in the mix was crushed basaltic stone aggregate with maximum size of $19 \mathrm{~mm}$. the sample will be collected from query site and washed to avoid impurities and the aggregate were sieved by using sieving machine. Finally, the aggregate in each sieve size and physical property test; like gradation, specific gravity, water absorption, moisture content and unit weight of aggregates are measured and recorded in the provided table format.

Sieve analysis

Sieve analysis is a procedure for determination of the aggregate size distribution using a series of square or round openings which starts with largest openings at the top. For coarse aggregate the size are between $75 \mathrm{~mm}$ and $4.75 \mathrm{~mm}$ in size according to Ethiopian standard.

Table 1. sieve analysis for coarse aggregate.

\begin{tabular}{ll}
\hline Sieve Analysis & \\
\hline Sieve size & \% Passing \\
\hline $37.5 \mathrm{~mm}$ & 100 \\
$19 \mathrm{~mm}$ & 95.1 \\
$12.5 \mathrm{~mm}$ & 51.9 \\
$9.5 \mathrm{~mm}$ & 24.22 \\
$4.75 \mathrm{~mm}$ & 3.95 \\
\hline
\end{tabular}

Specific gravity and absorption capacity

Specific gravity of aggregate is made use of in design calculation of concrete mixes. Specific gravity is the ratio of the density of substance to the density of reference substance. Water absorption of coarse aggregate is one factor that can affect the $\mathrm{W} / \mathrm{C}$ ratio and workability of concrete.

Moisture content

The process To determine moisture content of coarse aggregate sample was weighted and oven dried for about $24 \mathrm{hrs}$ at temperature of $105^{\circ} \mathrm{C}-110^{\circ} \mathrm{C}$, and the sample was removed from the oven dry machine and placed for about an hour in order to cool, then the sample was weighted and the ratio were calculated.
Table 2. Physical properties of course aggregate.

\begin{tabular}{lll}
\hline \multicolumn{2}{l}{ Physical properties } \\
\hline No & Test Description & Result \\
\hline 1 & Absorption Capacity & $1.71 \%$ \\
3 & Specific gravity & $2.74 \%$ \\
4 & Bulk Specific gravity (SSD) & $2.79 \%$ \\
5 & Apparent specific gravity & $2.87 \%$ \\
6 & Fineness Modulus & $2.24 \%$ \\
\hline
\end{tabular}

\subsubsection{Fine Aggregate}

The Fine aggregate used in the production of concrete is river sand. It was washed, sieved and tested for silt content. The fine aggregate used in the mix is with silt content of $2.74 \%$ and it meets the requirements set by Ethiopian standard requirements.

Silt content

ES (Ethiopian standard) recommends, if the silt content of the fine aggregate is greater than $6 \%$ it is recommended either to wash or to reject the sand. For this research the silt content is $2.74<6$, and accepted.

Sieve analysis

ES (Ethiopian standard) recommends, aggregate between size $9.5 \mathrm{~mm}$ and $150 \mu$ are classified under fine aggregate. The sand sample was tested and checked according to ES recomendation.

Table 3. Sieve result of fine aggregate.

\begin{tabular}{ll}
\hline Sieve size & \% Passing \\
\hline 9.5 & 100 \\
$4.75 \mathrm{~mm}$ & 98.5 \\
$2.36 \mathrm{~mm}$ & 87.6 \\
$1.18 \mathrm{~mm}$ & 62.3 \\
$600 \mu$ & 33.7 \\
$300 \mu$ & 14.8 \\
$150 \mu$ & 0.8 \\
pan & 0 \\
\hline
\end{tabular}

\subsubsection{Admixtures}

Super plasticizer admixture used for concrete to maintain workability conplast430, which is chloride free and has no effect on the strength of concrete as long as water/cement ratio is not changed. It's recommended to use in ranges of $1-$ 3 liter $/ 100 \mathrm{~kg}$ of cement.

\subsubsection{Water}

As a principle Portable water supplied by Addis Ababa city was used to prepare the mix.

\subsubsection{Glass Fibers}

Since E-Glass fiber was used for the research study with alkali content $<1 \%$ and with good tensile, stiffness and electrical properties E glass fibers have low impact resistance. Basically the properties of E- Glass fiber is as follows were used for this research with tensile strength:

1. Good electrical insulation

2. High strength

3. Low density

4. Good chemical resistance

5. Relatively insensitive to moisture

6. Low cost 


\subsubsection{Recycled Steel Fibers}

The pyrolysis process is the commonly used method to recycle tire which minimizes atmospheric emissions. The process starts with heating and/or burning in an enclosed pyrolysis plant chamber, this process producing fuel oil, steel wire and carbon black. The fuel oil can be used for different purposes including energy source and also the steel wire can be used for different purposes. Steel fibers recycled by method of pyrolysis are termed as pyrolysis recycled steel fiber any they are mostly contain black carbon on the surface. The tensile strength is not as much affected in the process.

The burning (pyrolysis) process was takes place with low temperature heat to protect the steel fiber from damage. The steel fibers were prepared by cutting the steel wire to the required length.

\subsection{Mix Preparation}

Mix preparation is done for C-25 concrete strength by proportioning ingredient of construction material that will satisfy the performance requirement.

For this research dangote cement were used in every concrete mix and a total of 8 mixes were made including the control mix for C-25 grade concrete and with glass and recycled steel fiber with a volume fraction of $0.5 \%, 1 \%$ and $1.5 \%$. For the production of all mixes DOE mix design method was applied. C-25 concrete grade were designed to give slump values $10-30 \mathrm{~mm}$ and a 7 and 28 days compressive strength of $25 \mathrm{Mpa}$ with a water to cement ratio of 0.54 .

The DOE mix design and the proportion for this mix series along with the volume of both Glass and recycled steel fiber with a constant length of $25 \mathrm{~mm}$ are presented in table 2 . There are 8 mix proportions of which two are for the control concrete and the rest for the varying volume of Glass and recycled steel fiber that were conducted to study the effect of the glass and recycled steel fiber on the concrete properties especially on the compressive, Flexural and split tensile strength.

\subsection{Specimen Preparation}

During specimen preparation it is necessary to bring the aggregate to saturated surface dry condition (SSD) certain amount of water were added to the measured aggregate. Saturated surface dry (SSD) where all pores are full, but the surface is completely dry is the widely used in most mix design and proportion standards in adjusting the required mixing water; hence, the water amount was determined by making adjustment using the aggregates moisture content and water absorption capacity so that the aggregates are saturated surface dried.

The mix was start with dray mix of fine aggregate, course aggregate and cement till the mix is properly mixed for about a minute. the fiber were added to in the dry mix time very carefully in order to avoid balling effect This was then follow the adding of two third of mixing water to the mixer and add the dry mix of ingredient and mixed for about three minutes.
Regarding placing and compaction, placing was started immediately after fresh mix and was done in two layers and compacted in vibrator table.

The specimens is prepared for testing of mechanical properties of hardened concrete were casted in cubic, cylinder and beam molds with size of $150 \mathrm{~mm} * 150 \mathrm{~mm} * 150 \mathrm{~mm}, \quad 150 \mathrm{~mm} * 300 \mathrm{~mm}$ and $100 * 100 * 500 \mathrm{~mm}$ were casted and placed on a vibrator table in order to obtain homogenous distribution of fibers and other concrete ingredients.

Cubes were used to determine the $7^{\text {th }}$ and $28^{\text {th }}$ days of compressive strength. Cylinder specimen was used to determine the $7^{\text {th }}$ and $28^{\text {th }}$ days of split tensile strength. Beam specimens were used to determine flexural strength of $7^{\text {th }}$ and $28^{\text {th }}$ days.

\subsection{Curing and Crushing}

Specimens after 24 hours of placing and compaction, samples were removed from their molds and placed in to water tank until the intended days for testing concrete compressive, flexural and split tensile for $7^{\text {th }}$ and $28^{\text {th }}$ days. The concretes are crushed for different tests and their load carrying capacity were determined and recorded.

\subsection{Laboratory Test Procedure}

Laboratory tests were conducted for both fresh and hardened concrete in accordance to Ethiopian standard for each mix and specimens.

\subsubsection{Testing for Fresh Concrete}

Slump test depending on Ethiopian standard were conducted for each mix at fresh state. Control mix gave slump values varies between $10-30 \mathrm{~mm}$ and concrete with RSF and Glass fibers gave slump values varies from 0 to 10 $\mathrm{mm}$.

\subsubsection{Testing for Hardened Concrete}

Compressive strength test were conduct by a compression testing machine with $3000 \mathrm{KN}$ capacity. The $7^{\text {th }}$ and $28^{\text {th }}$ days of compressive strength was conducted for each mix. Compressive strength test was conducted by using cylinder and cube specimens depending on ASTM C39 provide standard test method. In this specific research cube specimen with dimension of $15 \mathrm{~cm} * 15 \mathrm{~cm} * 15 \mathrm{~cm}$ size were used. Three specimens were tested for each mix and the mean value is taken as a compressional strength of the mix.

Flexural tensile strength and failure load under flexural loading test were conducted by using flexural testing machine (Tecno Test) with $100 \mathrm{KN}$ capacity. It is a measure of an amount of stress or force that a beam can withstand from bending failure. Two points loading were used to determine the flexural tensile strength of the $7^{\text {th }}$ and $28^{\text {th }}$ days for each mix specimen with size of $10 \mathrm{~cm} * 10 \mathrm{~cm} * 50 \mathrm{~cm}$. Two specimens were tested for each mix and the mean value is taken as a Flexural tensile strength of the mix.

Split tensile strength test conducted on concrete cylinder is a method used to to determine tensile strength of concrete. 
The cylinder specimens were used to test split tensile tests with a diagonal direction with compressional testing machine. The $7^{\text {th }}$ and $28^{\text {th }}$ days of Split tensile strength was conducted for each mix specimen with glass and recycled steel fibers. Three specimens were tested in accordance with ASTM C496 standard for each mix and the mean value is taken as a Split tensile strength of the mix.

\section{Test Result and Discussion}

\subsection{General}

For all specimens type their result was discussed in the following sections. Both glass and recycled steel fiber are effective in improving the mechanical properties of concrete. Both Glass and recycled steel fiber reinforced concrete test were compared relative to control specimen. The Result include slump test at fresh state and compressive, Flexural tensile, Split tensile at hardened state.

\subsection{Test Result for Fresh Concrete}

\subsubsection{Slump Test}

The freshly mixed concrete workability is a measure of ease of placing, resistance to segregation of concrete and its ability to be mixed, handled, transported and most importantly, placed and consolidated with a minimal loss of homogeneity and minimal entrapped air. Among the several tests available the slump test is a common, convenient and inexpensive test. Predicting the workability of SFRC is difficult because of the large number of parameters involved. Two factors which influence significantly the characteristics of SFRC in its fresh state are the aggregate content, and fiber geometry and volume fraction. The influence of aspect ratio and volume fraction of fiber on the properties of fresh concrete is investigated in this research work.

\subsubsection{Slump Test Value}

All the control mixes (plain concretes) were mixed to give a slump value of $10-30 \mathrm{~mm}$. And it was proved to be so for the trial mixes gives the value between $10-30 \mathrm{~mm}$ of slump, but when the recycled fibers and glass fiber are added the slump value is highly decreasing from $10 \mathrm{~mm}-0 \mathrm{~mm}$.

Volume of fiber volume and aspect ratio has a crucial influence on both glass fiber and recycled steel fiber reinforced concrete on workability. The incrimination of fiber volume in a concrete reduce the workability of fresh concrete as measured by the slump test.
Table 4. Slump Result for fresh Concrete.

\begin{tabular}{llll}
\hline No & Concrete Grade & Mix & Slump value \\
\hline 1 & C 25 & Control Concrete & $30-60$ \\
& & $0.5 \% \mathrm{RSF}$ & 37 \\
2 & C 25 with RSF & $1 \% \mathrm{RSF}$ & 25 \\
& & $1.5 \% \mathrm{RSF}$ & 5 \\
& & $0.5 \% \mathrm{GF}$ & 52 \\
3 & C 25 with GF & $1 \% \mathrm{GF}$ & 43 \\
& & $1.5 \% \mathrm{GF}$ & 10 \\
\hline
\end{tabular}

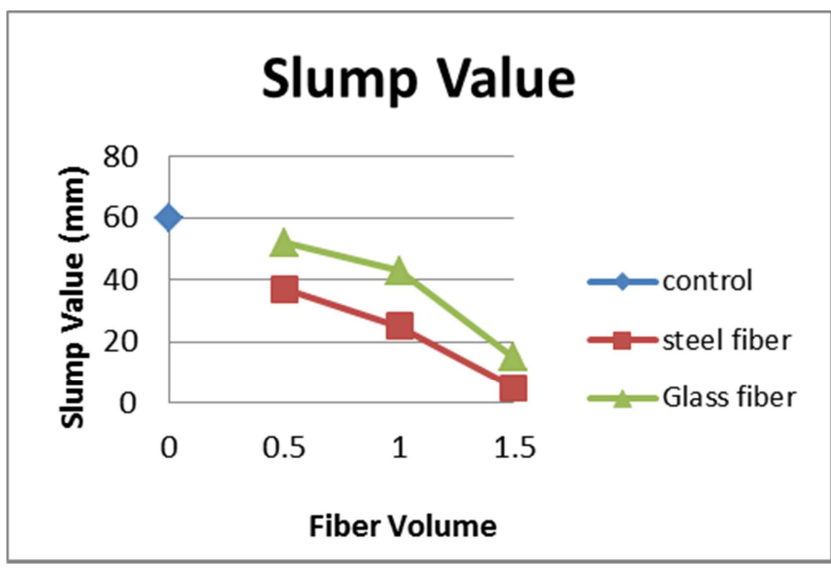

Figure 1. Comparison of slump Value 10

\subsection{Test Result for Hardened Concrete}

\subsubsection{Compressive Strength}

The $7^{\text {th }}$ and $28^{\text {th }}$ day's compressive strengths were determined in a laboratory Test procedure. The compressive strength as the mean of three specimens tested and the relative strength gain or loss compared to that of the nominal mix.

As reported in Table 5, the $7^{\text {th }}$ and $28^{\text {th }}$ day mean compressive strength for the plain control mix is found to be 27.92MPa. In this mix series addition of steel fiber volume ranging from $0.5 \%, 1 \% 1.5 \%$ has resulted mean compressive strength values varying from $28.9,29.41,27.78 \mathrm{MPa}$ with a maximum relative strength loss and gain of $0.5 \%$ for $1.5 \%$ volume of SFRC, $5.34 \%$ for $1 \%$ SFRC respectively.

In this mix series addition of Glass fiber volume ranging from $0.5 \%, 1 \% 1.5 \%$ has resulted mean compressive strength values varying from $28.85,30.12,29.85 \mathrm{MPa}$ with a maximum relative strength gain of $7.87 \%$. An increase in compressive strength shown in glass fiber with volume of $1 \%$.

Table 5. $28^{\text {th }}$ days Compressive strength test result.

\begin{tabular}{|c|c|c|c|c|c|c|c|}
\hline \multicolumn{4}{|c|}{ Recycled steel fiber RC } & \multicolumn{4}{|c|}{ Glass fiber RC } \\
\hline Mix code & no & compressive strength & Mean & Mix code & no & compressive strength & Mean \\
\hline \multirow{4}{*}{ Ms0 } & 1 & 28.07 & \multirow{4}{*}{27.92} & \multirow{3}{*}{$\operatorname{Mg} 0$} & 1 & 28.07 & \multirow{3}{*}{27.92} \\
\hline & 2 & 27.27 & & & 2 & 27.27 & \\
\hline & 3 & 28.42 & & & 3 & 28.42 & \\
\hline & 1 & 29.74 & & \multirow{3}{*}{$\mathrm{Mg} 1$} & 1 & 29.49 & \multirow{3}{*}{28.85} \\
\hline \multirow[t]{2}{*}{ Ms1 } & 2 & 28.28 & \multirow[t]{2}{*}{28.9} & & 2 & 30.12 & \\
\hline & 3 & 28.67 & & & 3 & 29.96 & \\
\hline \multirow{2}{*}{ Ms2 } & 1 & 28.83 & \multirow{2}{*}{29.41} & \multirow{2}{*}{$\mathrm{Mg} 2$} & 1 & 30.25 & \multirow{2}{*}{30.12} \\
\hline & 2 & 29.92 & & & 2 & 30.18 & \\
\hline
\end{tabular}




\begin{tabular}{|c|c|c|c|c|c|c|c|}
\hline \multicolumn{4}{|c|}{ Recycled steel fiber RC } & \multicolumn{4}{|c|}{ Glass fiber $\mathrm{RC}$} \\
\hline Mix code & no & compressive strength & Mean & Mix code & no & compressive strength & Mean \\
\hline \multirow{4}{*}{ Ms3 } & 3 & 29.47 & \multirow{4}{*}{27.78} & \multirow{4}{*}{ Mg3 } & 3 & 29.92 & \multirow{4}{*}{29.85} \\
\hline & 1 & 27.39 & & & 1 & 29.79 & \\
\hline & 2 & 27.87 & & & 2 & 29.29 & \\
\hline & 3 & 28.06 & & & 3 & 30.47 & \\
\hline
\end{tabular}

\subsubsection{Split Tensile Strength}

The 7 and 28 days Split Tensile strengths were determined in a laboratory Test procedure. Table 6 shows the 28th day compressive strength as the mean of three specimens tested and the relative strength gain or loss to that of the control mix.

As reported in the graph the mean Split tensile strength of control plain concrete is found to be 2.33 and Split tensile strength for SRFC values ranging from 2.4, 2.52, $2.39 \mathrm{MPa}$ and glass fiber ranging from $2.39 \mathrm{MPa}, 2.61$ and $2.50 \mathrm{MPa}$ with a relative split tensile strength gain of $8.15 \%$ for SRSC and $12.02 \%$ for GFRC was obtained by inclusion of fibers of $1 \%$ volume shows a better result. Both fiber additions to concrete improve the split tensile strength and $1 \%$ is an optimum blend percentage for performance gain of concrete.

Table 6. $28^{\text {th }}$ days Split tensile strength test result.

\begin{tabular}{|c|c|c|c|c|c|c|c|}
\hline \multicolumn{4}{|c|}{ Recycled steel fiber } & \multicolumn{4}{|l|}{ Glass fiber } \\
\hline Mix code & no & Split Tensile strength (mpa) & Mean & Mix code & no & Split Tensile strength (mpa) & Mean \\
\hline \multirow{4}{*}{ Ms0 } & 1 & 2.17 & \multirow{3}{*}{2.33} & \multirow{3}{*}{$\mathrm{Mg} 0$} & 1 & 2.17 & \multirow{3}{*}{2.33} \\
\hline & 2 & 2.29 & & & 2 & 2.29 & \\
\hline & 3 & 2.52 & & & 3 & 2.52 & \\
\hline & 1 & 2.44 & \multirow{3}{*}{2.40} & \multirow{3}{*}{$\mathrm{Mg} 1$} & 1 & 2.47 & \multirow{3}{*}{2.39} \\
\hline \multirow[t]{3}{*}{ Ms1 } & 2 & 2.35 & & & 2 & 2.34 & \\
\hline & 3 & 2.40 & & & 3 & 2.37 & \\
\hline & 1 & 2.61 & \multirow{3}{*}{2.52} & \multirow{3}{*}{$\mathrm{Mg} 2$} & 1 & 2.58 & \multirow{3}{*}{2.61} \\
\hline \multirow[t]{3}{*}{ Ms2 } & 2 & 2.53 & & & 2 & 2.32 & \\
\hline & 3 & 2.42 & & & 3 & 2.93 & \\
\hline & 1 & 2.39 & \multirow{3}{*}{2.39} & \multirow{3}{*}{$\mathrm{Mg} 3$} & 1 & 2.49 & \multirow{3}{*}{2.50} \\
\hline \multirow[t]{2}{*}{ Ms3 } & 2 & 2.41 & & & 2 & 2.57 & \\
\hline & 3 & 2.38 & & & 3 & 2.45 & \\
\hline
\end{tabular}

\subsubsection{Flexural Strength}

The 7 and 28 days Flexural strengths were determined in a laboratory Test procedure. Table 7 shows the $7^{\text {th }}$ and $28^{\text {th }}$ day compressive strength as the mean of three specimens tested and the relative strength increment or decrement to that of the control mix.

Flexural strength is basically adopted by two commonly used forms of the flexure test; the two point loading or center point loading. The former is generally preferred for many materials, but the latter is often used where greater testing simplicity is required. In this research work the flexural tensile strength of all mixes was determined as clarified in using a two point loading. As reported in the graph the flexural tensile strength of control plain concrete is found to be 5.7 and Flexural tensile strength of concrete values is I between $6.53 \mathrm{MPa}$ to $6.82 \mathrm{MPa}$ for recycled steel fiber and $6.62-7.10 \mathrm{mpa}$ for glass fiber reinforced concrete with a relative flexural tensile strength increment of $19.64 \%$ to $24.56 \%$ was obtained by addition of fibers of $1 \%$ volume for recycled steel fiber and glass fibers respectively.

Table 7. $28^{\text {th }}$ days Flexural Strength test result.

\begin{tabular}{|c|c|c|c|c|c|c|c|}
\hline \multicolumn{4}{|c|}{ Recycled steel fiber } & \multicolumn{4}{|c|}{ Glass fiber } \\
\hline Mix code & no & Flexural Strength (mpa) & Mean (mpa) & Mix code & no & Flexural Strength (mpa) & Mean (mpa) \\
\hline \multirow{2}{*}{ Ms0 } & 1 & 5.87 & \multirow{2}{*}{5.7} & \multirow{2}{*}{$\operatorname{Mg} 0$} & 1 & 5.87 & \multirow{2}{*}{5.7} \\
\hline & 2 & 5.53 & & & 2 & 5.53 & \\
\hline \multirow{2}{*}{ Ms1 } & 1 & 6.29 & \multirow{2}{*}{6.53} & \multirow{2}{*}{ Mg1 } & 1 & 6.37 & \multirow{2}{*}{6.62} \\
\hline & 2 & 6.77 & & & 2 & 6.87 & \\
\hline \multirow{2}{*}{ Ms2 } & 1 & 6.41 & \multirow{2}{*}{6.82} & \multirow{2}{*}{ Mg2 } & 1 & 6.37 & \multirow{2}{*}{7.10} \\
\hline & 2 & 7.23 & & & 2 & 7.83 & \\
\hline \multirow{2}{*}{ Ms3 } & 1 & 6.63 & \multirow{2}{*}{6.75} & \multirow{2}{*}{$\mathrm{Mg} 3$} & 1 & 6.95 & \multirow{2}{*}{7.04} \\
\hline & 2 & 6.87 & & & 2 & 7.13 & \\
\hline
\end{tabular}




\subsection{Direct Cost Benefit Analysis}

The feasibility of using recycled steel fiber and glass fiber concrete is evaluated compare with the conventional concrete. The feasibility of RSFRC and GFRC is evaluated by material and production cost reduction. Material cost comparison between conventional concrete, recycled steel fiber and glass fibers are summarized in the table below.

Table 8. Cost Break down summary.

\begin{tabular}{ll}
\hline Summary & \\
\hline material & total price (birr) \\
\hline nominal concrete & 1780.7 \\
Recycled steel fiber concrete & 1940.7 \\
Glass fiber concrete & 3460.7 \\
\hline
\end{tabular}

Glass fiber 105birr $/ \mathrm{kg}$.

Recycled steel fiber $15 \mathrm{birr} / \mathrm{kg}$.

The material cost of Recycled steel fiber is lower than that of glass. The cost per $\mathrm{m}^{3}$ production of concrete by using recycled steel fiber is lower with about $78 \%$ than glass fiber reinforced concrete.

\section{Conclusion and Recommendation}

\subsection{Conclusion}

This research Work experimentally investigates mechanical properties of recycled tire wire fiber and glass fibers mixed structural concrete. Next, results of this research work are presented.

1. Addition of both recycled steel fibers and glass fibers improved mechanical properties of concrete to be specific, use of recycled steel fiber and glass fibers increased flexural property of concrete by $19.64 \%$ and $24.56 \%$ whereas split tensile strength of concrete is enhanced by $8.15 \%$ and $12.02 \%$, respectively. Similarly, compressive strength of concrete is improved by $5.34 \%$ and $7.87 \%$ for addition of recycled steel fiber and glass fibers, respectively.

2. The optimum blend percentage of recycled tire fiber and glass fiber for enhanced performance gain mechanical properties of concrete is one percent.

3. Addition of recycled steel fiber in a concrete is cost effective which reduce cost by $78 \%$ when compared to glass fiber reinforced concrete with a small difference on the mechanical property performance.

\subsection{Recommendation}

1. This research work results affirm use of recycled steel fiber and glass fibers improves mechanical properties of concrete, however, further, research investigation is recommended in order to have a more in-depth insights in long term effects of using recycled steel fiber and glass fibers additions in structural concrete production.

2. The interesting results confirm the application of concrete reinforced with steel fibers extracted from waste tire to replace the industrially manufactured glass fibers.
However, further, research work is still necessary in order to have a more in-depth understanding of the material properties and to evaluate possible practical applications.

\section{References}

[1] Shetty M. S., Concrete Technology Theory and Practice, Revised Edition, New Delhi, 2005.

[2] Neville A. M., Properties of Concrete, Fifth edition, Pearson Education Ltd, 2013.

[3] ACI Committee 544, "Evaluation of strength Test result of concrete," ACI 214R-02, 2002.

[4] ACI Committee 544, Guide for Specifying, Proportioning, Mixing, Placing, and Finishing Steel Fiber Reinforced Concrete, ACI 544. 3R-93.

[5] European Commission, Council directive 1999/31/EC on "the landfill of waste," Official Journal of the European Communities, 1999.

[6] European Commission, Directive 2000/76/EC of the European Parliament and of the Council of 4 December 2000 on "incineration of waste," Official Journal of the European Communities, 2000, pp. 91-111.

[7] Hylands K. N. and Shulman V., "Civil engineering applications of tires." Viridis Report VR5, Transport Research Laboratory, Crow Thorne, 2003.

[8] W. H Tayler, concrete Technology and practice, 4th edition, 1997.

[9] Steven H. Kosmatka, Beatrix Kerkhoff, William C. Panarese, "Design and Control of Concrete Mixtures," 14th edition, Portland Cement Association, 2003.

[10] Rizwan H. W., Farhan Hussain Wagan, Imran Hussain Wagan, Ghulam Hussain Wagan, "The Effect of Waste Tire Steel Fibers distribution Characteristics on the Flexural Strength of Concrete with Improving Environmental Impact in Pakistan". American Journal of Applied Scientific Research".2017, V. 3, No. 5, pp. 49-55.

[11] Nguyen Van Chanh "Steel Fiber Reinforced Concrete" Ho Chiminh City University of Technology, pp 108-116.

[12] Islam, G. S., Gupta S. D. "Evaluating plastic shrinkage and permeability of polypropylene fiber reinforced concrete," International Journal of Sustainable Built Environment, 2016, V. 2, pp. 345-354.

[13] Serrano. R., Cobo. A., Prieto. M. I., de las Nieves González. M. "Analysis of fire resistance of concrete with polypropylene or steel fibers. Construction and building materials," 2016, V. 122, pp. 302-309.

[14] Mastali, M., Dalvand, A., "Fresh and hardened properties of self- compacting concrete reinforced with hybrid recycled steel-polypropylene fiber, Journal of Materials in Civil Engineering,” 2017, V. 29, pp. 301-312.

[15] M. A. Aiello, F. Leuzzi, G. Centonze, A. Maffezzoli (2009) "Use of steel fibers recovered from waste tyres as reinforcement in concrete: Pull-out behavior, compressive and flexural strength" Department of Innovation Engineering, University of Salento, via Monteroni, 73100 Lecce, Italy. 
[16] K. Srinivasa Rao, S. Rakeshkumar, A. Laxmi Narayana," Comparison of Performance of Standard Concrete And Fiber Reinforced Standard Concrete Exposed To Elevated Temperatures, "American Journal of Engineering Research, V. 2, pp. 20-26.

[17] Ziaaddin Zamanzadeha, Lúcio Louren çoband Joaquim," Recycled steel fibre reinforced concrete failing in bending and in shear" American Journal of Engineering Research, V. 2, pp. 21-32.

[18] Methuke. V, "Strengthening of reinforced concrete beams using glass fiber reinforced polymer composite," International journal of engineering research and technology, 2013, V. 2.

[19] Ronak. P, Jayeshkumar. P, "A study on glass fiber as an additive in concrete to increase concrete tensile strength," Global research analysis, 2013, V. 2.

[20] J. D. chaitanya, G. Abhilash,"Experimental studies on glass fiber concrete," International journal of engineering research and technology 2016, V. 5, pp. 100-104.

[21] P. arulsivananthen, "Experimental Study on usage of class-E glass fiber in the cement concrete," International journal of engineering research and technology, 2015, V. 4.

[22] Prakash N, Sejal. P, "strength and durability aspect study of glass fiber reinforced concrete with flay ash," International journal of futuristic trends in engineering and technology, 2014, V. 1.

[23] Waste tire shredding management, https://www.wastepyrolysisplant.net.

[24] ACI Committee 544, "state of The art report on fiber reinforced concrete," ACI 544 1. R-96, 2002.

[25] California Integrated Waste Management Board, “Assessment of Markets for Fiber and Steel Produced From Recycling Waste Tyres," Sacramento, 2003. 